\title{
Eficacia in-vitro de un colutorio elaborado con aceite esencial de la hoja de ishpingo Ocotea quixos (Lam.) Kostern. ex O.C.Schmidt y clavo de olor Syzygium aromaticum (L.) Merr. \& L.M. Perry
}

\author{
In-vitro efficacy of a mouthwash made with essential oil of leaf ishpingo \\ Ocotea quixos (Lam.) Kostern. ex O.C.Schmidt and clove \\ Syzygium aromaticum (L.) Merr. \& L.M. Perry
}

Tatiana de los Ángeles Mosquera y Teresa Melania Veloz Vera

Centro de Investigación y Valoración de la Biodiversidad -CIVABI, Universidad Politécnica Salesiana, Quito, Ecuador Autora para correspondencia: tmosquera@ups.edu.ec

Artículo recibido el 15 de marzo de 201 I. Aceptado, tras revisión el 30 de mayo de 201 I.

\begin{abstract}
Resumen
En función de la CMB del aceite esencial de ishpingo (0.26\%) y del aceite esencial de clavo de olor (1.56\%) frente a Streptococcus mutans y Streptococcus pyogenes, determinada mediante el método de dilución en medio líquido, se elaboró un colutorio. Con el objeto de determinar la eficacia in vitro del colutorio elaborado, se sembraron en el agar infusión cerebro y corazón las cepas de Streptococcus mutans ATCC 25175 y Streptococcus pyogenes ATCC 19615. Utilizándose el método de difusión en medio sólido, se colocaron $25 \mu \mathrm{L}$ de los colutorios elaborados y de enjuagues bucales comerciales sobre discos de papel filtro y se incubaron las placas a $37^{\circ} \mathrm{C}$ durante 24 horas para S. pyogenes y 48 horas para S. mutans. De acuerdo a los resultados, los colutorios elaborados produjeron halos de inhibición de crecimiento de colonias bacterianas. El análisis estadístico de los datos mediante la prueba no paramétrica de Kruskal Wallis en el software Statistix 8.0 determinó que existen diferencias entre los colutorios elaborados y los enjuagues bucales comerciales.
\end{abstract}

Palabras clave: streptococcus mutans, Streptococcus pyogenes, colutorio, eficacia, in vitro, antibacteriano.

\begin{abstract}
Considering the CMB of the ishpingo essential oil (0.26\%) and the essential oil of clove (1.56\%) against the Streptococcus mutans and the Streptococcus pyogenes, applying the dilution method in liquid medium we developed a mouthwash. In order to determine the effectiveness of our mouthwash, prepared in vitro, we introduce in the brain and heart infusion agar strains of Streptococcus mutans ATCC 25175 and ATCC 196I5 Streptococcus pyogenes. Using the diffusion method on solid medium, we placed $25 \mu \mathrm{L}$ of our mouthwash and commercial mouthwashes on discs of filter paper and we incubated at $37^{\circ} \mathrm{C}$ for 24 hours S. pyogenes strains and 48 hours for S. mutans strains. According to the results, the mouthwash we produced growth inhibition zones of bacterial colonies. For the statistical analysis of the samples we used the nonparametric Kruskal Wallis test on Statistix 8.0 software and determined that there are differences between our mouthwash and the commercial products.
\end{abstract}

Keywords: Streptococcus mutans, Streptococcus pyogenes, mouthwash, in vitro efficiency.

Forma sugerida de citar:

Mosquera,T.y Veloz Vera,T.20I I. Eficacia in-vitro de un colutorio elaborado con aceite esencial de la hoja de ishpingo Ocotea quixos (Lam.) Kosterm. ex O.C.Schmidt y clavo de olor Syzygium aromaticum (L.) Merr. \& L.M. Perry. La Granja.Vol. I3(I): 3I-4I. ISSN: I390-3799. 


\section{Introducción}

La caries, así como las infecciones de garganta, son de las enfermedades más comunes en el mundo. Los microorganismos presentes en la placa dental o placa bacteriana están íntimamente relacionados a estas patologías, siendo Streptococcus mutans y Streptococcus pyogenes los agentes etiológicos que causan la caries y las infecciones de garganta respectivamente; por lo cual, el control de estos microorganismos es de mucha importancia para evitar la enfermedad y en la actualidad se lo realiza mediante el uso de productos tópicos o locales (enjuagues bucales y colutorios) que contienen sustancias antimicrobianas para eliminar la flora bacteriana de la placa dental.

En los últimos años, el uso de las plantas como fuente de principios activos antimicrobianos es de gran interés para los investigadores puesto que las ventajas son diversas: fácil acceso, bajo costo y sobre todo, pocos efectos colaterales indeseables.

La especie Ocotea quixos (Lam.) Kosterm. ex O.C.Schmidt, pertenece a la familia Lauraceae y es conocida en Ecuador con diferentes nombres: ishpink, ispingu, ishpingo o canelón. El hábitat natural de este árbol es el bosque húmedo tropical de la Amazonía ecuatoriana, crece entre los 310 y $1.250 \mathrm{msnm}$, destaca por ser endémico de este lugar. 0 . quixos. Es un árbol perenne de 2-5 $\mathrm{m}$ de altura; lámina de la hoja de $14,5-23,5 \mathrm{~cm}$ de longitud y $3,5-6 \mathrm{~cm}$ de ancho, olor a canela; flor de color blanco-verdosa; cáliz persistente de seis sépalos y fruto ovalado de $4 \mathrm{~cm}$ de longitud cualidades que lo caracterizan. La especie florece y fructifica cada dos años, cuando alcanza mínimo veinte años de madurez (Noriega y Dacarro, 2008).

Por otro lado, la especie Syzygium aromaticum (L.) Merr. \& L.M. Perry, pertenece a la familia Myrtaceae $y$ es conocida con diferentes nombres vernáculos como: clavo de olor, árbol del clavo, clavo, clavero. Esta especie se trata de un árbol perenne caracterizado por presentar una altura cercana a los $15 \mathrm{~m}$; hojas simples, ovado-oblongas, lisas y brillantes de $5-12 \mathrm{~cm}$ de largo; flores púrpura, con una longitud de $1-1,75 \mathrm{~cm}$ agrupadas de a tres en cimas compactas ubicadas en el extremo de las ramas; yemas tiernas rosadas; frutos rojizos o amarillo-pálidos, en forma de baya alargada de $\mathrm{I}-2 \mathrm{~cm}$ de largo. La planta florece cada 2-3 años.

La presente investigación pretende demostrar de una manera clara y sencilla la alternativa que se tiene en el uso de los aceites esenciales de las hojas de ishpingo (Ocotea quixos (Lam.) Kosterm. ex O.C.Schmidt) y clavo de olor (Syzygium aromaticum (L.) Merr. \& L.M. Perry) en la formulación de un colutorio (enjuague bucal) que inhiba el crecimiento de S. mutans y S. pyo- genes, puesto que, existen investigaciones previas que demuestra el elevado poder antibacteriano de los aceites esenciales de las hojas de ishpingo y clavo de olor (Noriega y Dacarro 2008; Alonso 2007).

Esta investigación se realizó con el objeto de determinar la eficacia antibacteriana in vitro del colutorio elaborado frente a cuatro enjuagues bucales comerciales (Listerine, Encident, Oraldine y Colgate Plax) mediante el método de difusión en medio sólido.

\section{Materiales y métodos}

\section{I Sitio de investigación}

La investigación se realizó en los meses de 2010 y enero de $20 \mathrm{II}$ en el laboratorio de Microbiología del CIVABI (Centro de Investigación y Valoración de la Biodiversidad) de la Universidad Politécnica Salesiana, Sede Quito, Campus El Girón.

\subsection{Obtención de los microorganismos se- leccionados para la investigación}

Los microorganismos a utilizar (Streptococcus mutans ATCC 25175 y Streptoccocus pyogenes ATCC 196I5) se obtuvieron del cepario del laboratorio de Microbiología del CIVABI de la UPS.

\subsection{Obtención de los aceites esenciales uti- lizados en la investigación}

El aceite esencial de las hojas de ishpingo Ocotea quixos (Lam.) Kosterm. ex O.C.Schmidt fue proporcionado por la Fundación Chankuap, ubicada en Macas, provincia de Morona Santiago. Se lo obtuvo por medio de una destilación por arrastre de vapor de las hojas de la especie Ocotea quixos.

El aceite esencial de clavo de olor Syzygium aromaticum (L.) Merr. \& L.M. Perry se lo consiguió a través del Laboratorios Luque, ubicado en Guayaquil, provincia de Guayas. Este aceite se lo extrae de los botones florales o yemas sin abrir secas mediante una destilación por arrastre de vapor.

\subsection{Determinación in-vitro de la Concen- tración Mínima Bactericida (CMB) de los aceites esenciales mediante el méto- do de dilución en medio líquido}

Para evaluar la acción de los aceites esenciales de la hoja de ishpingo y de clavo de olor sobre Streptococcus 
mutans y Streptococcus pyogenes en esta investigación, se determinó la Concentración Mínima Bactericida (CMB) de los aceites esenciales a través de la técnica de dilución en medio líquido, que contempla enfrentar a los microorganismos mencionados a diferentes concentraciones de los aceites. El procedimiento se realizó según la metodología general propuesta por Gamazo et al. que se describe a continuación.

\section{a. Preparación del caldo de cultivo}

Siguiendo las instrucciones del fabricante se preparó $50 \mathrm{ml}$ de TSB (Tripticasa Soya Broth), adicionado con el $2 \%$ de Tween 20 , con el objetivo de que los aceites esenciales formen una emulsión con el caldo de cultivo (Noriega y Dacarro, 2008). Se procedió a distribuir $\mathrm{Iml}$ del caldo en 50 tubos de ensayo con tapa rosca $(13 \times 100 \mathrm{~mm})$, producto que se esterilizó en un autoclave marca Tuttnauer $387 \mathrm{OM}$, a $121^{\circ} \mathrm{C}$ durante 15 minutos.

Una vez esterilizados los tubos de ensayo con TSB se formó series de diez tubos que fueron etiquetadas con la información como: fecha, microorganismo a inocular y número de tubo (del I al I0). Este proceso se realizó por duplicado para cada aceite esencial a evaluar.

Aparte, en un tubo de ensayo vacío y estéril (etiquetado como tubo 0), se colocó $2 \mathrm{ml}$ del aceite esencial a evaluar. Seguidamente, con la ayuda de una pipeta desechable estéril, se tomó I $\mathrm{ml}$ del contenido del tubo 0 , se transfirió al tubo I y se homogenizó. Se repitió la operación con el tubo $2, y$ así sucesivamente hasta llegar hasta el tubo 10.

De esta manera, los aceites esenciales se incorporaron al caldo de cultivo de manera que cada tubo de ensayo tuvo una concentración conocida del aceite esencial a ensayar.

\section{b. Preparación del inóculo bacteriano}

En varios tubos de ensayo, a partir de las cepas ATCC previamente activadas, se preparó un cultivo de cada una de las cepas a utilizarse en $5 \mathrm{ml}$ del medio Tripticasa Soya Broth y se incubó a $37^{\circ} \mathrm{C}$ durante 24 horas para S. pyogenes y 48 horas para S. mutans. Transcurrido el tiempo de incubación, en una centrífuga marca Selecta, se centrifugaron los tubos de ensayo a 3.500 revoluciones por minuto (rpm), durante 20 minutos. Inmediatamente, se eliminó el sobrenadante y se resuspendió el pellet obtenido en $4 \mathrm{ml}$ de solución fisiológica estéril ( $\mathrm{NaCl}$ 0,9\%). Seguidamente, en un tubo con $10 \mathrm{ml}$ de solución fisiológica estéril, se adicionó el inóculo obtenido en el paso anterior, y se reguló la densidad óptica hasta obtener una absorbancia similar a 0,200 a una longitud de onda de $655 \mathrm{~nm}$; de esta manera se obtiene un inóculo bacteriano equivalente a I x $10^{8} \mathrm{UFC} / \mathrm{ml}$ (Maldonado y Dacarro, 2006).

Las lecturas de turbidez del inóculo se realizaron en el Espectrofotómetro UV/Visible marca Shimatzu Modelo MINI 1240.

\section{c. Inoculación de microorganismos}

Una vez obtenidos los tubos seriados con caldo de cultivo y diferentes concentraciones de aceite esenciales se procedió a inocular los microorganismos. Para el caso de S. pyogenes se inoculó $10 \mu \mathrm{L}$ de la suspensión bacteriana obtenida anteriormente en cada tubo de ensayo, de manera que se inoculan $1 \times 10^{6}$ UFC/ml. Para S. mutans, se inoculó $1000 \mu \mathrm{L}$ de la suspensión bacteriana en cada tubo de ensayo, se inoculan $\mathrm{I} \times 10^{8} \mathrm{UFC} / \mathrm{ml}$.

La diferencia en el volumen de suspensión inoculada para cada cepa radica en que $S$. pyogenes muestra un buen crecimiento in vitro, por su parte $S$. mutans es un microorganismo exigente $y$ en una prueba previa, al inocular $10 \mu \mathrm{L}$ de la suspensión bacteriana, no se obervó crecimiento, por esta razón se decidió aumentar el volumen y al igual que la cantidad de UFC a inocular.

\section{d. Incubación}

Posteriormente de la inoculación de las suspensiones bacterianas en cada tubo, se procedió a incubar los tubos en una estufa marca Shel Lab a $37^{\circ} \mathrm{C}$. Los tubos con S. pyogenes se incubaron durante 24 horas, mientras que los tubos con S. mutans se lo hizo durante 48 horas.

\section{e. Siembra en BHIA (Brain and Heart Infusion Agar)}

Transcurrido el tiempo de incubación adecuado, con la ayuda de un hisopo estéril, se tomó una muestra de cada tubo y se sembró en cajas petri que contenían BHIA, preparado según las indicaciones del fabricante. Se incubaron las cajas en una estufa marca Shel Lab a $37^{\circ} \mathrm{C}$. Las cajas que contenían las muestras de S. pyogenes se incubaron durante 24 horas, mientras que las de $S$. mutans se lo hizo por un tiempo de $\mathbf{4 8}$ horas. Cumplido el tiempo de incubación se observaron las cajas en las cuales no existe crecimiento bacteriano y se define la CMB de cada aceite frente a cada microorganismo. 


\subsection{Formulación del colutorio con aceite esencial de la hoja de ishpingo y clavo de olor}

Tomando en cuenta la CMB de los aceites esenciales y habiendo establecido un prototipo de preferencia sensorial (enjuague bucal Colgate Plax), se procedió a formular el colutorio. Dentro de la fórmula se consideraron las materias primas más importantes (Muñoz, 2000): un tensioactivo o detergente (lauril éter sulfato de sodio), sustancias humectantes (sorbitol y glicerina), un saborizante (sabor menta), un edulcorante (sacarina sódica), colorantes (verde menta y amarillo) y los principios activos (aceite esencial de la hoja de ishpingo y aceite esencial de clavo de olor). Las concentraciones utilizadas de cada materia prima están dentro de los rangos sugeridos por la bibliografía (Muñoz, 2000). Se elaboraron dos formulaciones, una con mayor y otra con menor contenido alcohólico con el objeto de evaluar si el alcohol ejerce algún efecto bactericida en la fórmula. En las Tablas I y 2 , se presenta la fórmula unitaria para una presentación de $80 \mathrm{ml}$ :

Tabla I. Fórmula Unitaria Colutorio A

\begin{tabular}{lcc}
\hline \multicolumn{1}{c}{ Sustancia } & Porcentaje & Cantidad \\
\hline Emal 70 (Lauril éter sulfato de sodio) & $3,75 \%$ & $3 \mathrm{~g}$ \\
Glicerina & $18,38 \%$ & $\mathrm{I4,7 \textrm {g }}$ \\
Sorbitol & $5,63 \%$ & $4,5 \mathrm{~g}$ \\
Sabor Menta & $4 \%$ & $3,2 \mathrm{~g}$ \\
Sacarina sódica & $0,04 \%$ & $0,032 \mathrm{~g}$ \\
Alcohol 96 & $12,5 \%$ & $10 \mathrm{ml}$ \\
Aceite esencial de la hoja de ishpingo & $0,26 \%$ & $0,2 \mathrm{I} \mathrm{ml}$ \\
Aceite esencial de clavo de olor & $1,56 \%$ & $\mathrm{I}, 25 \mathrm{ml}$ \\
Colorante verde & - & $\mathrm{I}$ gota \\
Colorante amarillo & - & $\mathrm{I}$ gota \\
Agua & $33,88 \%$ & c.s.p. $80 \mathrm{ml}$ \\
\hline Total & $100 \%$ & \\
\hline
\end{tabular}

Tabla 2. Fórmula Unitaria Colutorio B

\begin{tabular}{lcc}
\hline \multicolumn{1}{c}{ Sustancia } & Porcentaje & Cantidad \\
\hline Emal 70 (Lauril éter sulfato de sodio) & $3,75 \%$ & $3 \mathrm{~g}$ \\
Glicerina & $18,38 \%$ & $\mathrm{I4,7} \mathrm{g}$ \\
Sorbitol & $5,63 \%$ & $4,5 \mathrm{~g}$ \\
Sabor Menta & $4 \%$ & $3,2 \mathrm{~g}$ \\
Sacarina sódica & $0,04 \%$ & $0,032 \mathrm{~g}$ \\
Alcohol 96 & $6,25 \%$ & $5 \mathrm{ml}$ \\
Aceite esencial de la hoja de ishpingo & $0,26 \%$ & $0,2 \mathrm{ml}$ \\
Aceite esencial de clavo de olor & $\mathrm{I}, 56 \%$ & $\mathrm{I}, 25 \mathrm{ml}$ \\
Colorante verde & - & $\mathrm{I}$ gota \\
Colorante amarillo & - & $\mathrm{I}$ gota \\
Agua & $33,88 \%$ & c.s.p. $80 \mathrm{ml}$ \\
\hline Total & $100 \%$ & \\
\hline
\end{tabular}




\section{Elaboración del colutorio con aceite esencial de la hoja de ishpingo y aceite esencial de clavo de olor}

En primer lugar se procedió a pesar y medir todos los ingredientes de la fórmula. Seguidamente se mezcló el lauril éter sulfato de sodio junto con la glicerina, el sorbitol y el sabor menta en un agitador magnético a 800 rpm durante 10 minutos $y$, poco a poco, se añadieron las $3 / 4$ partes del disolvente (agua). En este punto se adicionaron la sacarina sódica y el colorante, se agitó durante cinco minutos hasta su completa disolución. Así se fue completando la formulación con el resto del disolvente hasta alcanzar el volumen total especificado en la fórmula. Posteriormente, se procedió al envasado y etiquetado del colutorio en un frasco de vidrio, dejándolo reposar por 24 horas para que desaparezca la espuma formada durante el proceso de manufactura. Finalmente, se realizaron los respectivos controles de calidad: organolépticos, físico-químicos y microbiológicos.

\subsection{Evaluación de la actividad antibacteria- na de los colutorios elaborados y los en- juagues bucales comerciales por el mé- todo de difusión en medio sólido}

En primera instancia se prepararon los inóculos de las bacterias utilizando la misma metodología utilizada para determinar la CMB de los aceites esenciales. Seguidamente se sumergió un hisopo de algodón en la suspensión bacteriana, se eliminó el exceso presionándolo sobre la pared interna del tubo, evitando así el exceso de inóculo. A continuación se inoculó la superficie de placas de agar BHIA con el hisopo pasándolo por toda la superficie en tres direcciones y se dejaron secar las placas por 5 minutos (Gamazo et al.).

Utilizando unas pinzas estériles se colocaron sobre las cajas petri discos de papel filtro $(6 \mathrm{~mm}$ de diá- metro) con $25 \mu \mathrm{l}$ de las siguientes muestras: Listerine, Colgate Plax, Encident, Oraldine, Colutorio A, Colutorio B, Blanco Positivo I (aceite esencial de la hoja de ishpingo puro), Blanco Positivo 2 (aceite esencial de clavo de olor puro), Blanco Negativo (fórmula del Colutorio $A$ sin aceites esenciales). Para que las muestras difundan en el medio de cultivo se dejaron reposar las placas durante 15 minutos a temperatura ambiente.

En este punto, en una estufa marca Shel Lab, se incubaron las placas en posición invertida a $37^{\circ} \mathrm{C}$ durante 24 horas para S. pyogenes y 48 horas para S. mutans. Transcurrido este tiempo, se midieron los diámetros de las zonas de inhibición con un pie de rey y se apuntaron los resultados. Todo el procedimiento descrito anteriormente, se realizó por quintuplicado tanto para S. mutans como para S. pyogenes. La bibliografía señala que el procedimiento se debe realizar mínimo por cuadriplicado con el fin de obtener un error menor al 10\% (CYTED 1995).

\section{Resultados y discusión}

\section{I Concentración Mínima Bactericida (CMB) de los aceites esenciales me- diante el método de dilución en medio líquido}

En la Tabla 3 se muestran los resultados de la CMB del aceite esencial de la hoja de ishpingo para $S$. mutans y $S$. pyogenes. Una vez que se sembraron alícuotas de cada tubo en cajas petri con BHIA se observa ausencia de crecimiento en concentraciones del aceite esencial superiores a $0.13 \%$ para S. mutans, concentración que corresponde al tubo 8. Para S. pyogenes se observa ausencia de crecimiento aún a la concentración más baja del aceite esencial $0,097 \%$. Con estos datos, definimos entonces que la CMB del aceite esencial de la hoja de inshingo frente $S$. pyogenes y S.mutans es de $0,26 \%$.

Tabla 3. Concentración Mínima Bactericida Aceite esencial de la hoja de ishpingo

\begin{tabular}{ccccccc}
\hline Dilución & $\begin{array}{c}\text { \% aceite } \\
\text { esencial }\end{array}$ & $\begin{array}{c}\text { S. pyogenes } \\
\text { Tubo I }\end{array}$ & $\begin{array}{c}\text { S. pyogenes } \\
\text { Tubo 2 }\end{array}$ & $\begin{array}{c}\text { \% aceite } \\
\text { esencial }\end{array}$ & $\begin{array}{c}\text { S. mutans } \\
\text { Tubo I }\end{array}$ & $\begin{array}{c}\text { S. mutans } \\
\text { Tubo 2 }\end{array}$ \\
\hline 0 & $100 \%$ & - & - & $100 \%$ & - & - \\
1 & $50 \%$ & - & - & $33,33 \%$ & - & - \\
2 & $25 \%$ & - & - & $16,67 \%$ & - & - \\
3 & $12,5 \%$ & - & - & $8,33 \%$ & - & - \\
4 & $6,25 \%$ & - & - & $4,17 \%$ & - & - \\
5 & $3,13 \%$ & - & - & $2,08 \%$ & - & - \\
6 & $1,56 \%$ & - & - & $1,04 \%$ & - & - \\
\hline
\end{tabular}




\begin{tabular}{ccccccc}
\hline Dilución & $\begin{array}{c}\text { \% aceite } \\
\text { esencial }\end{array}$ & $\begin{array}{c}\text { S. pyogenes } \\
\text { Tubo I }\end{array}$ & $\begin{array}{c}\text { S. pyogenes } \\
\text { Tubo 2 }\end{array}$ & $\begin{array}{c}\text { \% aceite } \\
\text { esencial }\end{array}$ & $\begin{array}{c}\text { S. mutans } \\
\text { Tubo I }\end{array}$ & $\begin{array}{c}\text { S. mutans } \\
\text { Tubo 2 }\end{array}$ \\
\hline 7 & $0,78 \%$ & - & - & $0,52 \%$ & - & - \\
8 & $0,39 \%$ & - & - & $0,26 \%$ & - & - \\
9 & $0,19 \%$ & - & - & $0,13 \%$ & + & + \\
10 & $0,097 \%$ & - & - & $0,07 \%$ & + & + \\
\hline
\end{tabular}

-: ausencia de crecimiento

+ : crecimiento

En la Tabla 4 se muestran los resultados de la CMB del aceite esencial de clavo de olor para S. mutans y $S$. pyogenes. Una vez que se sembraron alícuotas de cada tubo en cajas petri con BHIA se observa ausencia de crecimiento en concentraciones del aceite esencial superiores a $0,78 \%$ para $S$. pyogenes y $0,13 \%$ para S. mutans, concentraciones que corresponden a los tubos 6 y 8 respectivamente. Con estos datos definimos entonces que la CMB del aceite esencial clavo de olor frente S. pyogenes y S.mutans es de I,56\%.

Tabla 4. Concentración Mínima Bactericida Aceite esencial de clavo de olor

\begin{tabular}{|c|c|c|c|c|c|c|}
\hline Dilución & $\begin{array}{l}\% \text { aceite } \\
\text { esencial }\end{array}$ & $\begin{array}{c}\text { S. pyogenes } \\
\text { Tubo I }\end{array}$ & $\begin{array}{l}\text { S. pyogenes } \\
\text { Tubo } 2\end{array}$ & $\begin{array}{l}\% \text { aceite } \\
\text { esencial }\end{array}$ & S. mutans Tubo I & S. mutans Tubo 2 \\
\hline 0 & $100 \%$ & - & - & $100 \%$ & - & - \\
\hline I & $50 \%$ & - & - & $33,33 \%$ & - & - \\
\hline 2 & $25 \%$ & - & - & $16,67 \%$ & - & - \\
\hline 3 & $12,5 \%$ & - & - & $8,33 \%$ & - & - \\
\hline 4 & $6,25 \%$ & - & - & $4,17 \%$ & - & - \\
\hline 5 & $3,13 \%$ & - & - & $2,08 \%$ & - & - \\
\hline 6 & I,56\% & - & - & $1,04 \%$ & - & - \\
\hline 7 & $0,78 \%$ & + & + & $0,52 \%$ & - & - \\
\hline 8 & $0,39 \%$ & + & + & $0,26 \%$ & - & - \\
\hline 9 & $0,19 \%$ & + & + & $0,13 \%$ & + & + \\
\hline 10 & $0,097 \%$ & + & + & $0,07 \%$ & + & + \\
\hline
\end{tabular}

-: ausencia de crecimiento

+ : crecimiento 


\subsection{Formulación y elaboración de los colutorios}

En la Tabla 5 se presentan las características organolépticas, físico-químicas y microbiológicas de los colutorios elaborados y de los enjuagues bucales comerciales.

Tabla 5. Características de los Colutorios elaborados y los enjuagues bucales comerciales

\begin{tabular}{|c|c|c|c|c|c|c|c|}
\hline & & Colutorio A & Colutorio B & Listerine & Encident & Oraldine & $\begin{array}{l}\text { Colgate } \\
\text { Plax }\end{array}$ \\
\hline \multirow{4}{*}{ Organolépticas } & Color & Verde limón & Verde limón & Amarillo & Rosado & Rojo & Verde \\
\hline & Olor & $\begin{array}{l}\text { Ishpingo y } \\
\text { menta }\end{array}$ & Ishpingo y menta & Alcohólico & Menta suave & Alcohólico & Mentolado \\
\hline & Sabor & $\begin{array}{l}\text { Picante, } \\
\text { ishpingo }\end{array}$ & Picante, ishpingo & Picante & Mentolado & Amargo & $\begin{array}{c}\text { Dulce, } \\
\text { mentolado }\end{array}$ \\
\hline & Apariencia & $\begin{array}{l}\text { Líquido } \\
\text { transparente }\end{array}$ & $\begin{array}{l}\text { Líquido } \\
\text { transparente }\end{array}$ & $\begin{array}{l}\text { Líquido } \\
\text { transparente }\end{array}$ & $\begin{array}{l}\text { Líquido } \\
\text { transparente }\end{array}$ & $\begin{array}{l}\text { Líquido } \\
\text { transparente }\end{array}$ & $\begin{array}{l}\text { Líquido } \\
\text { transparente }\end{array}$ \\
\hline \multirow{3}{*}{ Físico-químicas } & Densidad & 1,0507 & 1,0615 & 0,9682 & $\mathrm{I}, 027 \mathrm{I}$ & 0,9916 & 1,0426 \\
\hline & $\begin{array}{l}\text { Índice de } \\
\text { refracción }\end{array}$ & 1,382 & 1,382 & 1,352 & $\mathrm{I}, 348$ & 1,345 & $\mathrm{I}, 364$ \\
\hline & $\mathrm{pH}$ & 8 & 8 & 4 & 8 & 4 & 6 \\
\hline \multirow{3}{*}{ Microbiológicas } & $\begin{array}{c}\text { Aerobios } \\
\text { totales }\end{array}$ & 0 UFC & 0 UFC & 0 UFC & 0 UFC & 0 UFC & 0 UFC \\
\hline & $\begin{array}{c}\text { Coliformes } \\
\text { totales }\end{array}$ & 0 UFC & 0 UFC & 0 UFC & 0 UFC & 0 UFC & 0 UFC \\
\hline & $\begin{array}{l}\text { Mohos y } \\
\text { levaduras }\end{array}$ & 0 UFC & 0 UFC & 0 UFC & 0 UFC & 0 UFC & 0 UFC \\
\hline
\end{tabular}

\subsection{Actividad antibacteriana de los} colutorios elaborados y los enjuagues bucales comerciales por el método de difusión en medio sólido

En la Tabla 18, se muestran los resultados de los halos de inhibición $(\mathrm{mm})$ que mostraron los colutorios elaborados y los enjuagues bucales comerciales usados como muestras.

Los resultados obtenidos muestran que Listerine no es capaz de inhibir el crecimiento de $S$. mutans ni de S. pyogenes, ya que no se observa ningún halo de inhibición. Estos datos concuerdan con la investigación realizada porValentina Camejo y publicada en la revista Acta Odontológica Venezolana, Volumen 37, $\mathrm{N}^{\circ} 2$, Venezuela, 1999.

Tanto el Colutorio A como el B, presentan un halo de inhibición promedio de $0,88 \mathrm{~mm}$ frente a $S$. mutans. El Colutorio A muestra un halo de inhibición promedio de $\mathrm{I} \mathrm{mm}$ frente a $S$. pyogenes mientras que el Colutorio B, para este mismo microorganismo, muestra un halo de inhibición promedio de $1,02 \mathrm{~mm}$.

Encident muestra un halo de inhibición promedio de $3,22 \mathrm{~mm}$ frente a $S$. mutans y $4,88 \mathrm{~mm}$ frente a $S$. pyogenes. Estos halos, son superiores frente a los presentados por los Colutorios A y B.

Oraldine presenta un halo de inhibición promedio de $0,25 \mathrm{~mm}$ frente a $S$. mutans y $0,36 \mathrm{~mm}$ frente a S. pyogenes. Los halos de inhibición de los Colutorios A y $B$ son superiores a estos.

Colgate Plax exhibe un halo de inhibición promedio de $0,17 \mathrm{~mm}$ frente a $S$. mutans y $14,68 \mathrm{~mm}$ frente a S. pyogenes. Los Colutorios A y B presentan un halo superior frente a $S$. mutans pero al mismo tiempo inferior para S. pyogenes.

El blanco negativo no presenta ningún halo de inhibición lo que demuestra que efectivamente los aceites esenciales de la hoja de ishpingo y clavo de olor son las sustancias que inhiben el crecimiento de los microorganismos ya que, como se mencionó con 
anterioridad, se usó como blanco negativo la misma fórmula del Colutorio A (con mayor contenido alcohólico) pero sin adicionar los aceites esenciales.

El blanco positivo I (aceite esencial A4 al 100\%) mostró un halo de inhibición promedio de $0,86 \mathrm{~mm}$ para S. mutans y I,06 mm para S. pyogenes. Estos halos son muy similares a los presentados por los Coluto$\operatorname{rios} \mathrm{A}$ y $\mathrm{B}$.

El blanco positivo 2 (aceite esencial A5 al 100\%) mostró un halo de inhibición promedio de $3,45 \mathrm{~mm}$ para S. mutans y $3 \mathrm{~mm}$ para S. pyogenes. Estos halos son superiores a los exhibidos por los Colutorios A y B.

Tabla 6.Actividad antibacteriana de los colutorios elaborados y los enjuagues bucales comerciales

\begin{tabular}{|c|c|c|c|c|c|c|c|c|c|}
\hline \multirow[b]{2}{*}{ Microorganismo } & \multicolumn{9}{|c|}{ Diámetro de los halos de inhibición (mm) } \\
\hline & Listerine & Encident & Oraldine & $\begin{array}{l}\text { Colgate } \\
\text { Plax }\end{array}$ & $\begin{array}{c}\text { Colutorio } \\
\text { A }\end{array}$ & $\begin{array}{c}\text { Colutorio } \\
\text { B }\end{array}$ & $\begin{array}{c}\text { Blanco } \\
\text { negativo }\end{array}$ & $\begin{array}{c}\text { Blanco } \\
\text { positivo } \\
\text { (A4) }\end{array}$ & $\begin{array}{c}\text { Blanco } \\
\text { positivo } \\
\text { (A5) }\end{array}$ \\
\hline $\begin{array}{l}\text { S. mutans } \\
\text { repetición I }\end{array}$ & 0 & 4 & 0,3 & 0,2 & 1 & I & 0 & 1 & 4 \\
\hline $\begin{array}{c}\text { S. mutans } \\
\text { repetición } 2\end{array}$ & 0 & 3,7 & 0,4 & 0,3 & 1 & 1 & 0 & I & 4,4 \\
\hline $\begin{array}{c}\text { S. mutans } \\
\text { repetición } 3\end{array}$ & 0 & 4 & 0,3 & 0,2 & 1,2 & I & 0 & 1,2 & 4 \\
\hline $\begin{array}{c}\text { S. mutans } \\
\text { repetición } 4\end{array}$ & 0 & 4 & 0,3 & 0,2 & 1 & 1 & 0 & 1 & 4,3 \\
\hline $\begin{array}{l}\text { S. mutans } \\
\text { repetición } 5\end{array}$ & 0 & 3,6 & 0,2 & 0,1 & I,I & I,3 & 0 & 1 & 4 \\
\hline $\begin{array}{l}\text { S. pyogenes } \\
\text { repetición I }\end{array}$ & 0 & 5 & 0,4 & 15 & I & 1 & 0 & I & 3 \\
\hline $\begin{array}{l}\text { S. pyogenes } \\
\text { repetición } 2\end{array}$ & 0 & 5 & 0,4 & 13,6 & I & 1 & 0 & I & 3,2 \\
\hline $\begin{array}{l}\text { S. pyogenes } \\
\text { repetición } 3\end{array}$ & 0 & 4,4 & 0,3 & 14,8 & I & I,I & 0 & I & 2,8 \\
\hline $\begin{array}{l}\text { S. pyogenes } \\
\text { repetición } 4\end{array}$ & 0 & 5 & 0.3 & 15 & 1 & I & 0 & 1 & 3 \\
\hline $\begin{array}{l}\text { S. pyogenes } \\
\text { repetición } 5\end{array}$ & 0 & 5 & 0.4 & 15 & 1 & I & 0 & 1.3 & 3 \\
\hline
\end{tabular}

\subsection{Análisis estadístico de la actividad antibacteriana de los colutorios elaborados y los enjuagues bucales comerciales}

El análisis estadístico de los resultados obtenidos en el estudio de la actividad antibacteriana de los colutorios elaborados y los enjuagues bucales comerciales se realizó mediante el Software Statistix 8.0. Para este tipo de casos, frecuentemente se realiza la prueba estadística paramétrica del Análisis de Varianza de una Vía, sin embargo, esta prueba es útil siempre y cuando los datos obtenidos sean normales. En esta investiga- ción, los datos obtenidos no cumplen con esta premisa por tal razón, se procedió a realizar la prueba de Kruskal Wallis ya que reemplaza a la paramétrica Análisis de Varianza de una Vía.

\subsection{Prueba de Kruskal Wallis contrastando los diámetros del halo de inhibición generados por los enjuagues bucales para Streptococcus mutans}

En esta prueba se plantea como hipótesis nula $\left(\mathrm{H}_{0}\right)$ que los seis enjuagues bucales utilizados en el estudio de la actividad antibacteriana tienen medianas del 
diámetro de los halos de inhibición estadísticamente similares. Por otra parte la hipótesis alternativa $(\mathrm{Ha})$ será que el valor de la mediana del diámetro del halo de inhibición generado por al menos uno de estos enjuagues bucales es diferente a los generados por los otros enjuagues. Se trabajó con un nivel de significancia (alfa) del 0,05. Los resultados emitidos por Statistix 8.0 se presentan en la Tabla 7 .

Tabla 7. Análisis de Varianza no paramétrico de una vía de Kruskal-Wallis

\begin{tabular}{lcc}
\hline $\begin{array}{c}\text { Enjuague bucal } \\
\text { (Variable) }\end{array}$ & Mean Rank & $\begin{array}{c}\text { Sample Size } \\
\text { (Tamaño de la } \\
\text { muestra) }\end{array}$ \\
\hline Colgate Plax & 8,8 & 5 \\
Colutorio A & 20,8 & 5 \\
Colutorio B & 20,2 & 5 \\
Encident & 28,0 & 5 \\
Listerine & 3,0 & 5 \\
Oraldine & 12,2 & 5 \\
Total & 15,5 & 30 \\
\hline
\end{tabular}

Se halló un valor del estadístico de Kruskal-Wallis $(\mathrm{H})$ de $27,6 \mathrm{I}$ y un valor de la probabilidad asociada al estadístico (P) de 0,00 (cero) por tal razón, se concluye que al menos uno de los enjuagues bucales está generando un halo de inhibición mucho más fuerte que los otros.

Para determinar cuál de los enjuagues está generando tal halo de inhibición se realizó una prueba extra de comparaciones entre las medianas de todos los pares posibles de enjuagues (Kruskal-Wallis AllPairwise Comparisons Test, Statistic 8.0), de la cual se obtuvieron los resultados que se pueden observar en la Tabla 8:

Tabla 8. Kruskal-Wallis All-Pairwise Comparisons Test

\begin{tabular}{lc}
\hline \multicolumn{1}{c}{ Enjuague bucal } & Perteneciente o afín al grupo \\
\hline Encident & $\mathrm{A}$ \\
Colutorio $\mathrm{A}$ & $\mathrm{AB}$ \\
Colutorio $\mathrm{B}$ & $\mathrm{AB}$ \\
Oraldine & $\mathrm{ABC}$ \\
Colgate Plax & $\mathrm{BC}$ \\
Listerine & $\mathrm{C}$ \\
\hline
\end{tabular}

Por tanto, hay tres grupos de enjuagues estadísticamente afines entre sí (por consiguiente también afines en su eficacia inhibitoria in vitro frente a $S$. mutans) y son: grupo A: Encident, el Colutorio A, el Colutorio
B y Oraldine; grupo B: El Colutorio A, el Colutorio B, Oraldine y Colgate Plax; grupo C: Oraldine, Colgate Plax y Listerine.

En otras palabras, separándose, por tanto, nítidamente la eficacia de los siguientes enjuagues: se obtiene que entre Encident y Colgate Plax: el primero es absolutamente mejor que el segundo. Entre Encident y Listerine: el primero es absolutamente mejor. Mientras que entre el Colutorio $A$ con Listerine: el primero es mejor, $y$ entre el Colutorio B con Listerine: el primero es mejor.

\subsubsection{Prueba de Kruskal Wallis contrastando los diámetros del halo de inhibición generados por los enjuagues bucales para Streptococcus pyogenes}

En esta prueba se plantea como hipótesis nula $\left(\mathrm{H}_{0}\right)$ que los seis enjuagues bucales utilizados en el estudio de la actividad antibacteriana tienen medianas del diámetro de los halos de inhibición estadísticamente similares. Por otra parte, la hipótesis alternativa $(\mathrm{Ha})$ será que el valor de la mediana del diámetro del halo de inhibición generado por al menos uno de estos enjuagues bucales es diferente a los generados por los otros enjuagues. Se trabajó con un nivel de significancia (alfa) del 0,05. Los resultados emitidos por Statistix 8.0 se presentan en la Tabla 9.

Tabla 9. Análisis de varianza no paramétrico de una vía de Kruskal-Wallis

\begin{tabular}{lcc}
\hline $\begin{array}{c}\text { Enjuague } \\
\text { bucal } \\
\text { (Variable) }\end{array}$ & Mean Rank & $\begin{array}{c}\text { Sample Size } \\
\text { (Tamaño de la } \\
\text { muestra) }\end{array}$ \\
\hline Colgate Plax & 28,0 & 5 \\
Colutorio A & 15,0 & 5 \\
Colutorio B & 16,0 & 5 \\
Encident & 23,0 & 5 \\
Listerine & 3,0 & 5 \\
Oraldine & 8,0 & 5 \\
Total & 15,5 & 30 \\
\hline
\end{tabular}

Se halló un valor del estadístico de Kruskal-Wallis $(\mathrm{H})$ de 28,46 y un valor de la probabilidad asociada al estadístico $(P)$ de 0,00 (cero), por tal razón, se concluye que al menos uno de los enjuagues bucales está generando un halo de inhibición mucho más fuerte que los otros.

Para determinar cual de los enjuagues está generando tal halo de inhibición se realizó una prueba 
extra de comparaciones entre las medianas de todos los pares posibles de enjuagues (Kruskal-Wallis AllPairwise Comparisons Test, Statistic 8.0), de la cual se obtuvieron los resultados que se pueden observar en la Tabla I0:

Tabla 10. Kruskal-Wallis All-Pairwise Comparisons Test

\begin{tabular}{cc}
\hline Enjuague bucal & \multicolumn{2}{c}{ Perteneciente o afín al grupo } \\
\hline Colgate Plax & $\mathrm{A}$ \\
Encident & $\mathrm{AB}$ \\
Colutorio B & $\mathrm{ABC}$ \\
Colutorio A & $\mathrm{ABC}$ \\
Oraldine & $\mathrm{BC}$ \\
Listerine & $\mathrm{C}$ \\
\hline
\end{tabular}

Por tanto, hay tres grupos de enjuagues estadísticamente afines entre sí (por consiguiente también afines en su eficacia inhibitoria in vitro frente a S. mutans) y son: grupo A: Colgate Plax, Encident, el Colutorio A y el Colutorio B; grupo B: Encident, el Colutorio B, el Colutorio A y Oraldine; grupo C: Colutorio B, Colutorio A, Oraldine y Listerine.

En otras palabras, separándose, por tanto, nítidamente la eficacia de los siguientes enjuagues: se obtiene que entre Colgate Plax y Oraldine: el primero es absolutamente mejor que el segundo. Entre Colgate Plax y Listerine: el primero es absolutamente mejor. Mientras que entre Encident y Listerine: el primero es mejor.

\section{Conclusiones}

Se confirma la actividad antimicrobiana del aceite esencial de la hoja de ishpingo, coincidiendo con la investigación realizada por Noriega y Dacarro (2008).

El aceite esencial de la hoja de ishpingo utilizado para la elaboración del colutorio (A4) presenta una CMB para $S$. mutans de $0,26 \%$ y una CMB para S. pyogenes menor a $0,097 \%$.

El aceite esencial de clavo de olor utilizado para la elaboración del colutorio (A5) presenta una CMB para $S$. mutans de $0,26 \%$ y una CMB para $S$. pyogenes de $1,56 \%$.

El colutorio elaborado presenta características organolépticas y físico-químicas similares a las de los enjuagues bucales comerciales.

Tanto Streptococcus mutans como Streptococcus pyogenes mostraron susceptibilidad frente al colutorio elaborado con aceite esencial de la hoja de ishpingo y clavo de olor.
El colutorio elaborado es más eficaz que Listerine y Oraldine en el control del crecimiento de S. mutans y S. pyogenes.

El enjuague bucal Encident es más eficiente que el colutorio elaborado en el control del crecimiento de S. mutans y S. pyogenes.

El enjuague bucal Colgate Plax es más eficiente que el colutorio elaborado en el control del crecimiento de $S$. pyogenes pero es menos eficiente en el control de S. mutans.

\section{Agradecimientos}

Un sincero agradecimiento a quienes apoyaron en el desarrollo de este trabajo investigativo: a la Universidad Politécnica Salesiana por el financiamiento de esta investigación a través de la III Convocatoria a Proyectos de Investigación; a María Elena Maldonado, Paco Noriega, Patricio Yánez por su acertada y desinteresada colaboración con sus conocimientos científico-técnicos. A todos/as que de una u otra manera hicieron posible que este trabajo llegue a su término.

\section{Referencias}

Alonso, J. 2007. Iera Reimpresión. Tratado de Fitofármacos y Nutraceúticos. Buenos Aires, Rosario: Editorial Corpus.

Bascones, A. y S. Morante. 2006. Antisépticos orales. Revisión de la literatura y perspectiva actual. Avances en periodoncia $18(1)$ : 3I-59.

Camejo, V. 1999. Sensibilidad in vitro de Streptococcus mutans a sanguinaria, compuesto fenólico y clorhexidina. Acta Odontológica Venezolana 37(2).

Cumbreño, S.y F. Pérez. 2004. Procedimientos Normalizados de Trabajo- Pn/L/Ff/007/00. Offarm 23(9): I56-I58.

CYTED. 1995. Manual de Técnicas de Investigación. Programa lberoamericano de Ciencia y Tecnología para el Desarrollo, Subprograma X: Química Fina Farmacéutica, Proyecto

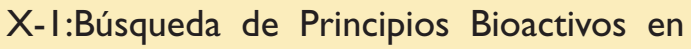
Plantas de la Región. 
Gamazo, C. et al. 3ra Edición. Manual práctico de Microbiología. Barcelona-España: Masson S.A.

Granados, R. y M. Villaverde. 2002. Segunda Edición. Microbiología Tomo II. Thomsom España: Editores. Paraninfo S.A.

Maldonado, M. y C. Dacarro. 2007. Análisis de la composición del aceite esencial de Myrcianthes rhopaloides (Kunth in H.B.K.) McVaugh, Myrtaceae, y evaluación de su actividad biológica. La Granja 6(I): 17-24.
Muñoz, M. 2000. Higiene bucodental. Pastas dentríficas y enjuagues bucales. Dermofarmacia en línea: 〈http://www.elsevier. es/watermark/ctl_servlet?_f $=$ I0\&pident_ articulo $=\mid 5465 \&$ pident_usuario $=0$ \&pident revista $=4 \&$ fichero $=04 \mathrm{v} 19 \mathrm{n} 03 \mathrm{a} 03008 \mathrm{pdf00} \mathrm{I}$. pdf\&ty $=75 \&$ accion $=$ L\&origen= doymafarma $\& w e b=w w w . d o y m a f a r m a . c o m \& l a n=e s\rangle$.

Noriega, P.y C. Dacarro. 2008. Aceite foliar de Ocotea quixos (Lam.) Kosterm.: actividad antimicrobiana y antifúngica. La Granja $7(1): 3-8$. 